Review paper

\title{
Monte Carlo studies in Gold Nanoparticles enhanced radiotherapy: The impact of modelled parameters in dose enhancement
}

\author{
Elena Vlastou *, Stefanos Diamantopoulos, Efstathios P. Efstathopoulos \\ 2nd Department of Radiology, University General Hospital "Attikon”, School of Medicine, National and Kapodistrian University of Athens, 1 Rimini Street, Haidari, \\ Athens 124 62, Greece
}

\section{A R T I C L E I N F O}

\section{Keywords:}

Gold Nanoparticles

Radiation Therapy

Monte Carlo simulations

Dose enhancement

\begin{abstract}
A B S T R A C T
Purpose: Over the last decades, Gold Nanoparticles (AuNPs) have been presented as an innovative approach in radiotherapy (RT) enhancement. Several studies have proven that the irradiation of tumors containing AuNPs could lead to more effective tumor control than irradiation alone. Studies with low kV photons and AuNPs conclude in encouraging results regarding the level of radioenhancement. However, experimental and theoretical studies with MV photons report controversial findings concerning the correlation between dose enhancement effect and tumor cell killing. The great variation in the experimental protocols and simulations complicates the comparison of their outcomes and depicts the need for limiting the variety of investigated parameters. Our purpose is to point out a possible direction for building realistic Monte Carlo (MC) models that could end up with promising results in MV photons RT enhancement.

Methods: We explored published in silico studies concerning AuNPs enhanced RT from 2010 to 2019. In this review, we discuss the different AuNPs and MV photon beams characteristics that have been reported and their effect in dose enhancement.

Results: AuNPs size, concentration, type of distribution along with photon beams energy and the presence of flattening filter in linear accelerators seem to be the major parameters that determine AuNPs radioenhancement in silico.

Conclusions: Prior to AuNPs clinical translation in photon radiotherapy, in silico studies should emphasize on nanodosimetry and track structure codes than condensed history ones. Toxicity estimation and biological aspects should be implemented in MC simulations so as to achieve accurate and realistic modelling of AuNPs driven RT.
\end{abstract}

\section{Introduction}

Radiation Therapy (RT) is one of the most common treatment modalities used in cancer treatment. It is estimated that approximately $50 \%$ of cancer patients will receive RT as part of their therapeutic strategy [1]. RT is based on photon or ion irradiation of tumor sites either by an external source such as a linear accelerator (external beam RT-EBRT), or by radioactive sources incorporated inside tumor lesions (Brachytherapy). The main challenge in RT is to deliver an adequate amount of dose (energy per unit mass) conformally to a target volume, while causing minimized toxicities to the nearby healthy structures. Over the last decades, several advances in RT (intensity modulated RT, stereotactic radiosurgery, proton therapy) have helped us produce more conformal dose distributions, treat sites in sizes of millimeters and decrease normal tissues side effects. Meanwhile, the introduction of image guided RT
(IGRT) has provided us a great tool to decrease the uncertainties arising from patients set up or organs motion, thus increase the precision in dose delivery. However the goal of improving the therapeutic ratio of RT, especially for the radioresistant tumors (e.g. sarcomas, glioblastomas) remains a major goal for radiation oncologists, radiobiologists and medical physicists.

The need to selectively increase the radiation dose and the induced damages to tumor sites while keeping dose to the adjacent healthy structures in certain defined limits, has triggered the investigation of Nanoparticles (NPs) as radiation sensitizers in RT. Among high atomic number NPs, gold NPs (AuNPs) have attracted scientific interest due to their unique properties, such as biocompatibility [2], selective absorption from cancerous cells [3] and low toxicity levels [4]. AuNPs can also be easily functionalized [5], while they have exhibited long term circulation [6] and the potential to reach the cell's nucleus [7]. Since the

\footnotetext{
* Corresponding author.

E-mail address: elenabls@med.uoa.gr (E. Vlastou).
} 
Table 1

A summary of the protocols followed in studies simulating AuNPs loaded regions irradiation with MV photon beams and their main results (2010-2019).

\begin{tabular}{|c|c|c|c|c|c|}
\hline \multirow[t]{2}{*}{ Authors } & \multicolumn{2}{|l|}{ MC code } & \multirow[t]{2}{*}{ Photon energy } & \multirow[t]{2}{*}{ Size/concentration } & \multirow[t]{2}{*}{ Main results } \\
\hline & Gold & $\begin{array}{l}\text { Water/ } \\
\text { Tissue }\end{array}$ & & & \\
\hline $\begin{array}{l}\text { Jones et al. } \\
2010[22]\end{array}$ & EGS & NOREC & $\begin{array}{l}{ }^{125} \mathrm{I},{ }^{103} \mathrm{Pd},{ }^{169} \mathrm{Yb},{ }^{192} \mathrm{Ir}, 50 \\
\mathrm{kVp}, 6 \mathrm{MV}\end{array}$ & $7 \mathrm{mg}_{\text {AuNPs }} \mathrm{g}^{-1}$ tumor & $\begin{array}{l}{ }^{125} \mathrm{I},{ }^{103} \mathrm{Pd},{ }^{169} \mathrm{Yb}, 50 \mathrm{kVp} \text { : microscopic dose around a } \\
\text { AuNP increased by factors ranging from } 10 \text { to } 1000 \\
\text { over } 30 \mu \mathrm{m} \text {. } \\
{ }^{192} \mathrm{Ir} \text { and } 6 \mathrm{MV} \text { : microscopic dose around a AuNP } \\
\text { increased by factors of } 10 \text { or less for distances greater } \\
\text { than } 1 \mu \mathrm{m} \text {. }\end{array}$ \\
\hline $\begin{array}{l}\text { Berbeco et al. } \\
2011 \text { [23] }\end{array}$ & \multicolumn{2}{|c|}{ Analytical calculation } & $6 \mathrm{MV}$ & 1 AuNP: 100 nm diameter & $\begin{array}{l}\text { Substantial local dose enhancement using } \\
\text { conventional linac }\end{array}$ \\
\hline $\begin{array}{l}\text { Lechtman } \\
\text { et al. } 2011 \\
\text { [24] }\end{array}$ & MCNP5 & PENELOPE & $\begin{array}{l}{ }^{103} \mathrm{Pd},{ }^{125} \mathrm{I} \text { brachytherapy seeds, } \\
{ }^{169} \mathrm{Yb},{ }^{192} \text { Ir HDR sources, } 300 \\
\mathrm{kVp}, 6 \mathrm{MV} \text { external sources }\end{array}$ & $1.9,5,30,100 \mathrm{~nm}$ diameter & $\begin{array}{l}\text { In order to double the deposited dose, one needs } 300 \\
\text { times greater number of AuNPs for MV photon beams } \\
\text { irradiation compared to low brachytherapy seeds } \\
\text { (possibly clinical infeasible). }\end{array}$ \\
\hline $\begin{array}{l}\text { Leung et al. } \\
2011 \text { [25] }\end{array}$ & Geant4 & & $50 \mathrm{kVp}, 250 \mathrm{kVp},{ }^{60} \mathrm{Co}, 6 \mathrm{MV}$ & 1 AuNP: 2, 50, $100 \mathrm{~nm}$ diameter & $\begin{array}{l}\text { In presence of AuNPs, increased secondary electron } \\
\text { production by } 10 \text { to } 2000 \\
\mathrm{kV} \text { photon beams interaction enhancement } \sim 2000 \\
\text { while for MV photons } \sim 10 \\
\text { Larger AuNPs diameter: greater dose deposition } \\
\text { Mean effective range of electron tracks: } 3 \mu \mathrm{m} \text { to } 1 \mathrm{~mm}\end{array}$ \\
\hline $\begin{array}{l}\text { McMahon } \\
\text { et al. } 2011 \\
\text { [12] }\end{array}$ & Geant4 & Geant4DNA & $6,15 \mathrm{MV}$ & 1 AuNP: $2 \mathrm{~nm}$ diameter & $\begin{array}{l}\text { AuNP ionization rate in MV region similar with that } \\
\text { in } \mathrm{kV} \text { region }\end{array}$ \\
\hline $\begin{array}{l}\text { Anijdan et al. } \\
2012 \text { [19] }\end{array}$ & MCNP4C & & $18 \mathrm{MV}$ & $5 \mathrm{mg}_{\text {AuNPs }} \mathrm{ml}^{-1}$ tumor & DEF of $8-12 \%$ \\
\hline $\begin{array}{l}\text { Amato et al. } \\
2013[26]\end{array}$ & Geant4 & & ${ }^{192} \mathrm{Ir}, 6 \mathrm{MV}$ & $0.2-10 \%$ weights & $\begin{array}{l}{ }^{192} \text { Ir: } 6-70 \% \text { relative dose enhancement } \\
6 \text { MV: } 1.6-18 \% \text { relative dose enhancement }\end{array}$ \\
\hline $\begin{array}{l}\text { Detappe et al. } \\
2013 \text { [27] }\end{array}$ & Analytical cal & ulation & $6 \mathrm{MV}$ & $30 \mathrm{mg}_{\text {AuNPs }} \mathrm{ml}^{-1}$ water & $\begin{array}{l}\text { The absence of FF leads to greater dose enhancement. } \\
\text { The effect of FF in dose enhancement depends on } \\
\text { photon field size and treatment depth. } \\
\text { Modulation of clinical beam causes less enhancement } \\
\text { than the corresponding open field. }\end{array}$ \\
\hline $\begin{array}{l}\text { Douglass et al. } \\
2013 \text { [28] }\end{array}$ & Geant4 & Geant4DNA & $\begin{array}{l}80 \mathrm{kVp} \\
6 \mathrm{MV}\end{array}$ & $\begin{array}{l}\text { AuNPs of } 400 \mathrm{~nm} \text { diameter } \\
\text { randomly distributed in cytoplasm, } \\
300 \mathrm{~nm} \text { gold layer around nucleus }\end{array}$ & $\begin{array}{l}\text { One order of magnitude greater dose enhancement in } \\
\text { case of } 80 \mathrm{kVp} \\
\text { Maximum dose enhancement in cell's nucleus in case } \\
\text { of } 300 \mathrm{~nm} \text { gold layer }\end{array}$ \\
\hline $\begin{array}{l}\text { Mesbahi et al. } \\
2013 \text { [29] }\end{array}$ & MCNPX & & $\begin{array}{l}50-120 \mathrm{keV},{ }^{60} \mathrm{Co} \text {, } \\
6,18 \mathrm{MV}\end{array}$ & $\begin{array}{l}30,50,100 \mathrm{~nm} \text { diameter } \\
7 \& 18 \mathrm{mg}_{\text {AuNPs }} \mathrm{g}_{\text {tumor }}^{-1}\end{array}$ & $\begin{array}{l}90 \mathrm{keV} \text { : greatest dose enhancement effect. } \\
\mathrm{kV} \text { range: } \mathrm{DEF} 1.4-3.7 \\
\mathrm{MV} \text { range: dose enhancement }<3 \% \text {. } \\
\text { DEF increases with concentration ( } \mathrm{kV} \text { region), size } \\
\text { has a negligible effect. }\end{array}$ \\
\hline $\begin{array}{l}\text { Tsiamas et al. } \\
2013 \text { [15] }\end{array}$ & Geant4 & $\begin{array}{l}\text { CEPXS/ } \\
\text { ONEDANT }\end{array}$ & $6 \mathrm{MV}$ & Clusters of $10,100 \mathrm{~nm}$ thickness & $\begin{array}{l}\text { DER more important in split-IMRT, larger depths, out } \\
\text { of field areas and/or FFF beams }\end{array}$ \\
\hline $\begin{array}{l}\text { Pakravan et al. } \\
2013[30]\end{array}$ & MCNPX & & $6 \mathrm{MV}$ (FF and FFF beams) & $\begin{array}{l}25,50,100,200 \mathrm{~nm} \text { diameter } \\
12,24,36 \mathrm{mg}_{\text {AuNPs }} \mathrm{g}_{\text {tumor }}^{-1}\end{array}$ & $\begin{array}{l}1-10 \% \text { dose enhancement depending on AuNPs } \\
\text { concentration and the presence/absence of FF }\end{array}$ \\
\hline $\begin{array}{l}\text { Zygmanski } \\
\text { et al. } 2013 \\
\text { [31] }\end{array}$ & Geant4 & $\begin{array}{l}\text { CEPXS/ } \\
\text { ONEDANT }\end{array}$ & $\begin{array}{l}11 \mathrm{keV}-1 \mathrm{MeV} \\
50 \mathrm{kVp}\end{array}$ & $\begin{array}{l}1 \text { cubic AuNP: } 100 \mathrm{~nm} \text { diameter, } \\
\text { cluster } 2 \times 2 \mu \mathrm{m}\end{array}$ & $\begin{array}{l}\text { Dose enhancement: almost isotropic about a } \\
\text { spherical AuNP, strongly dependent on the } \\
\text { simulation micro-geometry } \\
\text { Nonlinear relation between DER for a single and } \\
\text { multiple AuNPs }\end{array}$ \\
\hline $\begin{array}{l}\text { Lin et al. } 2014 \\
\quad[32]\end{array}$ & Geant4DNA & TOPAS & $\begin{array}{l}\text { Protons: } 10,25,50,100 \text { and } \\
150 \mathrm{MeV} \\
\text { Photons: } 50,100,150,200 \text { and } \\
250 \mathrm{keV} \text {, } \\
6 \mathrm{MV}\end{array}$ & 1 AuNP: $50 \mathrm{~nm}$ diameter & $\begin{array}{l}\text { Secondary electrons produced by } \mathrm{kV} \text { photons have } \\
\text { longest range in water than MV photons (and } \\
\text { protons). }\end{array}$ \\
\hline $\begin{array}{c}\text { Kakade et al. } \\
2015 \text { [33] }\end{array}$ & EGS & & $\begin{array}{l}100,150 \mathrm{kVp} \\
6,15 \mathrm{MV}\end{array}$ & $7,18 \mathrm{mg}_{\mathrm{AuNPs}} \mathrm{g}^{-1}$ tumor & $\begin{array}{l}\text { Average DEF values: } \\
100 \mathrm{kVp}: 1.86 \text { and } 2.91 \\
150 \mathrm{kVp}: 1.69 \text { and } 2.61 \\
6,15 \mathrm{MV} \text { : Negligible DEF }\end{array}$ \\
\hline $\begin{array}{l}\text { Lin et al. } 2015 \\
\quad[34]\end{array}$ & TOPAS & & $\begin{array}{l}\text { Protons: A spread out Bragg } \\
\text { peak beam with } 12.7 \mathrm{~cm} \text { range } \\
\text { and } 7 \mathrm{cmmodulation} \\
\text { Photons: } 150,250 \mathrm{kV}, 6 \mathrm{MV}\end{array}$ & $\begin{array}{l}2,10 \text { and } 20 \mathrm{~nm} \text { diameter } \\
\text { homogeneously distributed in blood } \\
\text { vessels or attached to vessels' inner } \\
\text { wall }\end{array}$ & $\begin{array}{l}\text { Negligible average dose enhancement for the whole } \\
\text { vasculature structure for MV photons and protons, } \\
\text { but high local dose escalation to areas of the blood } \\
\text { vessel that could lead to more effective tumor control }\end{array}$ \\
\hline $\begin{array}{l}\text { Koger et al. } \\
2016[35]\end{array}$ & PENELOPE & & $\begin{array}{l}20 \mathrm{keV}-6 \mathrm{MeV}, \\
100,200 \text {, and } 300 \mathrm{kVp} \text { in a } 360^{\circ} \\
\text { arc treatment. }\end{array}$ & $\begin{array}{l}2,20 \mathrm{~nm} \text { diameter } \\
0.8,15 \mathrm{mg}_{\text {AuNPs }} \mathrm{g}^{-1} \text { tumor }\end{array}$ & $\begin{array}{l}\text { Dosimetric advantage of low } \mathrm{kV} \text { arc therapy with } \\
\text { AuNPs over conventional } 6 \mathrm{MV}\end{array}$ \\
\hline $\begin{array}{l}\text { Khosravi et al. } \\
2016 \text { [36] }\end{array}$ & MCNP5 & & $\begin{array}{l}50,90 \mathrm{keV} \\
2,6 \mathrm{MV}\end{array}$ & $\begin{array}{l}15,50,100 \mathrm{~nm} \text { diameter } \\
7 \mathrm{mg}_{\text {AuNPs }} \mathrm{g}^{-1} \text { target }\end{array}$ & $\begin{array}{l}\text { DEF in keV range: } 1.69-2.66 \text { (highest at } 50 \mathrm{keV} \text { ) } \\
\text { DEF in MV range: } 1.08-1.10\end{array}$ \\
\hline $\begin{array}{l}\text { Hwang et al. } \\
2017 \text { [37] }\end{array}$ & MCNPX & & ${ }^{60} \mathrm{Co}, 4,6,10,15 \mathrm{MV}$ & $\begin{array}{l}25,50,75,100,125 \mathrm{~nm} \text { diameter } \\
7,18,30 \mathrm{mg}_{\text {AuNPs }} \mathrm{g}^{-1} \text { tumor }\end{array}$ & $\begin{array}{l}\text { AuNPs concentration has higher impact on DEF than } \\
\text { size }\end{array}$ \\
\hline $\begin{array}{l}\text { Keshavarz } \\
\text { et al. } 2019 \\
\text { [38] }\end{array}$ & MCNPX & & $\begin{array}{l}50,95,250 \mathrm{keV} \text { and } 4 \mathrm{MeV} \\
\text { photon }\end{array}$ & $\begin{array}{l}20,25,30,50,70,90,100 \mathrm{~nm} \\
18 \mathrm{mg}_{\text {AuNPs }} \mathrm{g}^{-1} \text { tumor }\end{array}$ & $\begin{array}{l}\text { DEF in keV range: } 1.06-2.9 \text { (highest at } 50 \mathrm{keV} \text { for } \\
100 \mathrm{~nm} \text { ) } \\
\text { DEF in MV range: } 1.01-1.08\end{array}$ \\
\hline
\end{tabular}

FF: flattening filter, FFF: flattening filter free. 
first study by Hainfeld et al. [3] who have found that the irradiation of AuNPs loaded tumors in mice could improve their 1 year survival rate from $20 \%$ to $86 \%$, over the last decade several in silico, in vitro and in vivo studies investigate AuNPs potential to enhance radiation damage effects [8-18]. Their results report that the irradiation of AuNPs injected sites leads to more efficient tumor control than irradiation alone. Outcomes of these studies have been expressed in various metrics of interest: dose enhancement factor (DEF), dose enhancement ratio (DER), survival rates, DNA damages, tumor growth inhibition etc. and they have proven different levels of AuNPs radiosensitization depending on their physical and chemical properties and radiation beam characteristics.

Any attempt for AuNPs implementation in clinical RT still has many obstacles to overcome. Key parameters such as AuNPs and radiation beam characteristics should be well correlated to the levels of radiosensitization in order to extract results that could lead to safety in AuNPs usage. Toxicity estimation, AuNPs biodistribution, route of administration, adaptation of nanodosimetry in Treatment Planning Systems (TPS), even cost issues need to be well established prior to any clinical translation.

The huge variety in experimental protocols used in literature, along with the fact that theoretical studies can provide a roadmap to guide experiments in cells and small animals have motivated us to search the literature for in silico studies in AuNPs radiosensitization. Our interest has been attracted by the different findings of theoretical studies compared to experimental ones concerning AuNPs efficacy in case of megavoltage (MV) photons irradiation [19-21]. While theoretical studies predict poor dose enhancement in MV region, in vitro and in vivo experiments report an increased radiosensitization. In order to explain the differences any straightforward comparison between results could not be safe. Therefore, considering that EBRT utilizes mostly MV photons, it is of great importance to gain clear results about whether it is possible to have a considerable level of dose amplification in this energy range.

Since it is still unclear under which conditions a trustworthy dose enhancement can be predicted when AuNPs loaded tumors are irradiated with MV photon beams, we aim to report the protocols that have been followed in MC simulations and their main findings. This study summarizes the in silico studies that investigate the effect of AuNPs and MV photon beam characteristics in physical dose increase. We highlight the parameters that do play a critical role in AuNPs driven photon RT in order for future researches to focus their attention on choosing the appropriate MC code and model certain aspects that could lead to substantial levels of dose enhancement in MV region. Our purpose is to offer a database containing the impact of each investigated parameter. We finally aim to suggest a guideline that could be used for building realistic Monte Carlo (MC) models that could end up with promising results in MV photons RT enhancement and lead to succesful in vivo translation.

\section{Methods}

This review study has explored the MC studies of the last decade concerning AuNPs in EBRT with photons. The search was performed in the databases of PubMed and Scopus, from 2010 to 2019. We used the following keywords: "Gold nanoparticles" and "Radiation Therapy" and "Monte Carlo". Synonyms and acronyms of the keywords were also used. From the 258 articles found, we focused on researches that have investigated the impact of AuNPs properties and radiation beam characteristics and searched their reference lists too. We further limited our review, exploring EBRT and emphasizing on studies that have included MV photon beams modelling (Table 1 ).

\section{Results}

From this literature search, we report the most discussed parameters that have been explored and seem to affect AuNPs ability to enhance radiation damage effects in silico. AuNPs size
[15,24,25,29-31,34,36-39], concentration [26,29,30,33,37,39] and the modelling of distribution [28,36,38-41] are the main AuNPs properties under investigation in literature. Photon energy [12,22,24-26,28,29,31-34,36-38], the presence of flattening filter (FF) in clinical photon beams $[15,27,30]$, simulation set up [42] and the user defined parameters [43] (Auger electrons activation, energy cut off, voxel size etc.) have been discussed in MC simulations from 2010 to 2019.

\subsection{AuNPs characteristics}

\subsubsection{Size}

AuNPs size seems to be of great interest since it affects both dose enhancement and cytotoxicity levels. One can assume that NPs with greater size would produce greater dose enhancement. Without a doubt, increased size means increased photons-AuNPs interactions and thus an increased number of secondary electrons. However, depending on photon energy, the produced Auger electrons and photoelectrons have a short range ( $<1 \mu \mathrm{m}$ and some hundreds of microns respectively). As a result, increasing AuNPs size, the phenomenon of secondary particles self absorption from gold is more likely to happen [25,44]. Interesting findings from Leung et al. [25] reported that when increasing AuNPs diameter, the amount of energy deposited inside them increases too. This phenomenon was found more apparent at the kilovoltage $(\mathrm{kV})$ region, while in MV range $100 \%$ of the energy was deposited outside the NPs in any size tested. They also mentioned that the effective range and mean energy of secondary electrons that are produced in the case of 2 $\mathrm{nm}$ AuNPs is lower compared to $50 \mathrm{~nm}$ and $100 \mathrm{~nm}$.

In their MC study Lechtman et al. [24] showed the effect of size in a wide range of photon energies ( $\mathrm{Pd}^{103}, \mathrm{I}^{125}, \mathrm{Yb}^{169}, 300 \mathrm{kVp}, \mathrm{Ir}^{192}, 6 \mathrm{MV}$ ). In every energy tested, they found five orders of magnitude greater number of photoelectric absorptions as AuNPs diameter increased from $1.9 \mathrm{~nm}$ to $100 \mathrm{~nm}$. However, they highlighted the fact that larger AuNPs are keener on absorbing the low energy electrons (Auger and delta) which seem to have a great biological effect.

In other studies, AuNPs size has a negligible effect in dose enhancement when photon energies are in MV range [29,30,36-38]. More specifically, Pakravan et al. [30] reported the greatest difference in DEF values of 1.046 and 1.056 in case of $25 \mathrm{~nm}$ diameter and $200 \mathrm{~nm}$ respectively for a concentration of $36 \mathrm{mg}_{\mathrm{AuNPs}} \mathrm{g}^{-1}$ tumor and a $6 \mathrm{MV}$ photon beam. Khosravi et al. [36] calculated a DEF of 1.09 when NPs with $15 \mathrm{~nm}$ diameter were tested and 1.10 when the same amount of NPs with $100 \mathrm{~nm}$ diameter were irradiated to a $6 \mathrm{MV}$ photon beam. The greatest increase (31\%) in DEF from 15 to $100 \mathrm{~nm}$ AuNPs was reported in case of $50 \mathrm{kV}$ photons irradiation. In a MC simulation published in 2017, the highest difference in DEF from 1.035 (25 nm diameter) to 1.047 (125 nm diameter) was observed for the highest concentration (30 $\mathrm{mg}_{\text {AuNPs }} \mathrm{g}^{-1}$ tumor) in a 4 MV photon beam [37].

Another research team [38] modelled the irradiation of a water phantom containing AuNPs (20-100 nm) for three types of distribution. AuNPs size had an important impact in DEF in the $50 \mathrm{keV}$ photon beam irradiation. In $4 \mathrm{MV}$ photon beam irradiation, they found a $1-4 \%$ increase in DEF when AuNPs diameter increased from $20 \mathrm{~nm}$ to $100 \mathrm{~nm}$. Mesbahi et al. [29] found the highest (but still slight) difference in DEF in case of $80 \mathrm{kV}$ photon beam and $18 \mathrm{mg}_{\text {AunPs }} \mathrm{g}^{-1}$ tumor. The DEF was 2 for $30 \mathrm{~nm}$ diameter and 2.3 for $100 \mathrm{~nm}$ diameter, when for the same concentration in $6 \mathrm{MV}$ a DEF of 1.01 was reported in any size tested. This work highlights the impact of AuNPs concentration than the size in radioenhancement when photon energies are above $80.7 \mathrm{keV}$ (Au Kedge).

Apart from the level of radiosensitization, AuNPs uptake from cells and the caused toxicity are considered closely correlated to their size [44]. In vitro results suggest though that AuNPs functionalization seem more important than size in terms of genotoxicity [45]. In any case, the proper AuNPs size that could cause sufficient enhancement in conjunction with minor toxicities is still under investigation. 


\subsubsection{Concentration}

A plethora of in silico studies have investigated the impact of AuNPs concentration in dose enhancement. For instance, Lechtman et al. [24] noted that in order to double the prescribed dose from an irradiation of 6 MV photons, approximately $2.17 \times 10^{7}$ AuNPs of $30 \mathrm{~nm}$ per tumor cell (that is equal to $1560-1700 \mathrm{mg} \mathrm{g}^{-1}$ tumor) are required. They underlined that this scenario is not feasible clinically, in contrast to an ${ }^{125} \mathrm{I}$ brachytherapy source irradiation where the number of AuNPs needed decreases to $1.83 \times 10^{3}$.

In their study, Pakravan et al. [30] calculated for the 6 MV photon beam a negligible increase in DEF from 1.011 to 1.056 when AuNPs concentration increased from $12 \mathrm{mg} \mathrm{g}^{-1}$ water to $36 \mathrm{mg} \mathrm{g}^{-1}$ water. A substantial increase in DEF $(\sim 1 \%)$ was published in a concentration range from 7 to $30 \mathrm{mg}_{\text {AuNPs }} \mathrm{g}^{-1}$ water [37]. Similarly, having performed water and GEL dosimetry respectively in the MV range, Mesbahi et al. [29] and Kakade et al. [33] reported a DEF of 1.01 for the examined concentrations of AuNPs $\left(7 \mathrm{mg} \mathrm{g}^{-1}\right.$ and $18 \mathrm{mg} \mathrm{g}^{-1}$ ). In the same studies, in $\mathrm{kV}$ range one can notice an almost twofold increase in DEF especially in the lowest energy photon beam ( $100 \mathrm{kV})$. In their MC simulation, Paro et al. [46] compared DEF from the irradiation of AuNPs (5, 10, 15, and 20 $\mathrm{mg}_{\text {AuNPs }} \mathrm{g}^{-1}$ tissue) evenly distributed through the cell. DEF increased with concentration in the $\mathrm{kV}$ region, while beyond $90 \mathrm{kV}$, the difference in DEF seems to reduce. However, a simulation of the irradiation of AuNPs loaded soft tissue in $6 \mathrm{MV}$ showed an increase in the average relative dose increment when gold occupied from 0.2 to $10 \%$ percent of soft tissue [26]. Similarly, for the same photon energy, Detappe et al. [27] found a linear increase in DEF with the increase of AuNPs concentration. Based on breast cells modelling, Cai et al. [47] pointed out that the amount of AuNPs ( $\mathrm{mg}_{\text {Au }} \mathrm{g}^{-1}$ tissue $)$ needed to double the absorbed dose from $\mathrm{X}$ rays in the $\mathrm{kV}$ region, is inversely proportional to the size of AuNPs.

\subsection{Photon beam characteristics}

\subsubsection{Energy}

Beam energy is a key parameter for AuNPs dose enhancement effect. AuNPs radiosensitization properties are based on the increased production of secondary electrons due to differences in the mass absorption coefficient of gold compared to that of soft tissue. Since this difference is higher in the $\mathrm{kV}$ range, it is expected that dose enhancement would be greater in lower energies. However, in clinical conditions where deep seated volumes need to be treated, MV photon therapy is the most common radiotherapeutic approach. Indeed, some theoretical studies in literature have reported a negligible effect in dose enhancement attributed to the presence of AuNPs in MV region [29,33,34,36]. Considering the fact that there exist evidence from in vitro and in vivo studies that demonstrate important dose enhancement or tumor growth inhibition in this region $[8,11,17,48,49]$, various research teams have performed MC calculations in a wide energy range.

Jones et al. [22] were the first to perform microdosimetric calculations in terms of dose enhancement due to the irradiation of AuNPs. They showed that the low energy photon sources examined such as $\left({ }^{125} \mathrm{I}\right.$, ${ }^{103} \mathrm{Pd},{ }^{169} \mathrm{Yb}$, or $50 \mathrm{kVp}$ x rays) lead to an increase of the microscopic dose around a AuNP by factors ranging from 10 to 1000 over $30 \mu \mathrm{m}$ compared to a factor of 10 or less for distances greater than $1 \mu \mathrm{m}$ in case of higher energy sources $\left({ }^{192} \mathrm{Ir}\right.$, and $\left.6 \mathrm{MV}\right)$.

Leung et al. [25] in their study examined the physical characteristics of the secondary electrons produced from the irradiation of a single AuNP (effective range, deflection angle, radial dose distribution, mean energy and interaction processes) as a function of photons energy and GNP size. For instance, using a $100 \mathrm{~nm}$ GNP they calculated that the mean effective ranges of secondary electrons generated by $50 \mathrm{kVp}, 250$ $\mathrm{kVp},{ }^{60} \mathrm{Co}$ and $6 \mathrm{MV}$ beams were 2.875, 29.23, 1290 and $1090 \mu \mathrm{m}$ respectively. They concluded that photon energies in the $\mathrm{kV}$ range are 2 or 3 orders of magnitude more effective concerning secondary electrons production, while in the MV range the produced ones have higher mean energy and smaller deflection angle. Lechtman et al. [24] came up to similar conclusions concerning beam energy effect. In their study, they calculated that in order to double the prescribed dose to the tumor, they needed approximately $10 \mathrm{mg}, 50 \mathrm{mg}$ and $1500 \mathrm{mg}$ AuNPs per $\mathrm{g}$ of tumor for ${ }^{125} \mathrm{I}, 300 \mathrm{kV}$ and $6 \mathrm{MV}$ irradiation. The last concentration is clinically infeasible to be achieved, indicating the efficiency of lower energy photon beams in a macroscopic level of measurements. Douglass et al. [28] performed measurements in different parts inside a cell in presence of AuNPs and they calculated DER ranging from 0.9 to 2.56 in case of 6 MV and 1.66-55.7 in the case of $80 \mathrm{kV}$ photon beams.

AuNPs enhanced arc radiation therapy (GEART) was investigated by Koger et al. [35]. The research team modelled the irradiation of tumors in a full arc treatment by monoenergetic and spectral photon beams in the presence of AuNPs. They reported that the $50 \mathrm{keV}$ (in case of monoenergetic) and the $200 \mathrm{keV}$ (in case of spectral) photon beam arc irradiation could increase the mean dose to tumors, compared to conventional 6 MV irradiation without AuNPs. Similar results for brain and breast tumors AuNPs enhanced RT with $\mathrm{kV}$ photons have been published from Sung et al. [50].

McMahon et al. [12] were among the first ones that tried to investigate the effect of MV photon sources in nanodosimetric levels. Comparing their MC study with in vitro results, they pointed out that even in the MV range, there exists a meaningful radiosensitization and highlighted the need for understanding the impact of AuNPs cellular localization in their radiosensitization effect. Closer to clinical conditions, Hwang et al. [37] investigated the radiosensitization effect of AuNPs upon high energy irradiation. The 4 and $6 \mathrm{MV}$ x rays showed a relatively high DEF $\sim 4 \%$ compared to the 10 and $15 \mathrm{MV}$ where DEF values ranged from $1 \%$ to $2 \%$.

\subsubsection{Flattening filter (FF)}

The effect of FF in the photon beam spectrum has been discussed and proved among various theoretical and experimental studies [51,52]. FF Free (FFF) beams are characterized by a softer photon spectrum, with more low energy photons compared to flat beams. The presence of lower energy photons in FFF beams has the potential to lead to higher DEF since energy seems to be one of the most important factors in dose enhancement effect [53]. Indeed, in a MC study the greatest dose enhancement has been noted in the case of FFF beams $(\sim 10 \%)$ while for the same AuNPs size and concentration, the presence of FF decreases the enhancement to $5.6 \%$ [30]. A two times greater DEF has been also reported in case of FFF compared to FF beams for any irradiation technique, whereas the greatest differences have been found in out of field areas [15]. The effect of FF in endothelial DEF (EDEF) has been studied in terms of treatment depth and photon field size [27]. While, in any treatment depth and for any field size, FFF beams resulted in a greater dose enhancement, EDEF for field sizes less than $5 \times 5 \mathrm{~cm}^{2}$ decreased slightly with depth in contrary to standard delivery where it seems to be constant. In field sizes greater than $5 \times 5 \mathrm{~cm}^{2}$, EDEF increased with depth either in presence or in absence of FF. The authors highlight the fact that the effect of removing the FF in dose enhancement becomes less important in small field sizes, with treatment depth increase, while the greatest percentage differences in EDEF between FFF and standard delivery have been reported for the smallest field sizes and shallowest depths.

\subsection{AuNPs localization and range of enhancement}

Plenty MC studies have examined the relationship between AuNPs localization and dose enhancement. As mentioned before, Douglass et al. [28] reported a sufficient dose enhancement when AuNPs are attached to cell's nucleous compared to cytoplasm. Cai et al. [47] modelled a certain number of AuNPs of the same characteristics at the extracellular space, surface, cytoplasm and nucleous of a breasts cell. Their analysis showed that for the purpose of doubling the deposited energy, one needs to place to cell's nucleous half of AuNPs amount that should place to the 
other regions. This fact is of great importance for the minimization of toxicity issues that may arise from AuNPs use.

In a macroscopic level, the optimum AuNPs position inside a tumor and the range of the produced secondary particles are crucial parameters in dose amplification. Lin et al. [32] used a $6 \mathrm{MV}$ linac spectrum to irradiate a water phantom containing one sigle GNP of $50 \mathrm{~nm}$ diameter. One of their findings was that DEF increased when the AuNP was irradiated with photon spectra calculated in larger depths explained by the scattering effect throughout the path.

Jones et al. [22] in their microdosimetry study calculated the secondary electrons spectra when a AuNPs loaded tumor $\left(7 \mathrm{mg}_{\text {AuNPs }} \mathrm{g}^{-}\right.$ $\left.1{ }_{\text {tumor }}\right)$ is irradiated inside a water region. The tumor was positioned in the central axis of the beam at a depth of 5-8 cm inside a water phantom. From the six photon sources that were used $\left({ }^{125} \mathrm{I},{ }^{103} \mathrm{Pd},{ }^{169} \mathrm{Yb},{ }^{192} \mathrm{Ir}, 50\right.$ $\mathrm{kVp}, 6 \mathrm{MV})$ three of them $\left({ }^{125} \mathrm{I},{ }^{103} \mathrm{Pd}, 50 \mathrm{kVp}\right)$ have an important impact in the region $30-40 \mu \mathrm{m}$. The dose point kernels extended beyond $100 \mu \mathrm{m}$ in case of ${ }^{169} \mathrm{Yb}$ and beyond $500 \mu \mathrm{m}$ in case of ${ }^{192} \mathrm{Ir}$ and $6 \mathrm{MV}$.

In another study, Leung et al. [25] irradiated a water cube containing one AuNP of different sizes by four beams $\left(50 \mathrm{kVp}, 250 \mathrm{kVp},{ }^{60} \mathrm{Co}, 6\right.$ MV). They concluded that even in case of the lowest photon beam source $(50 \mathrm{kVp})$, the range of the generated secondary particles was sufficient enough to reach all parts of a typical $10 \mu \mathrm{m}$ cell.

\subsection{Simulation models}

The dose enhancement property of AuNPs is attributed to the increase of low energy secondary particles that are locally produced upon $\mathrm{x}$ ray irradiation. This fact, indicates the need for accurate modelling of low energy particles interactions in a nanometer scale. Various MC codes have been used among studies in literature, using different simulation models.

\subsubsection{MC codes}

The most popular MC codes that have been used to model AuNPs enhanced RT with MV photons are Geant4 [12,15,25,26,28,31,32], EGSnrc [22,33,41], MCNP-X [29,30,37,38] and MCNP5 [24,36]. These condensed history $(\mathrm{CH})$ codes have been used in MC studies to describe photons interactions with AuNPs. In terms of water/tissue dosimetry, either $\mathrm{CH}[19,25,26,29,30,33,36-38]$ or track structure (TS) codes $[12,22,24,28,32]$ have been employed. Table 1 presents the MC codes that have been used in each case for each study.

Geant4 is a general purpose and open source simulation toolkit which has been used to describe particles interactions. Geant4 offers libraries which permit the modelling of electron transport down to very low energies, such as Penelope and Livermore. Penelope is valid from $100 \mathrm{eV}$ and Livermore from $250 \mathrm{eV}$ [54,55]. Incerti et al. [56] used Geant4 in order to simulate full Auger deexcitation cacades in case of AuNPs irradiation with $\mathrm{keV}$ photons and $\mathrm{MeV}$ protons. In favor of computational resources these models follow a $\mathrm{CH}$ approach, since they consider multiple instead of sequential single scatterings [57]. Lately, Geant4-DNA has been used for DNA damages evaluation [58,59] and nanodosimetric studies with AuNPs [12,28,32,60,61] since it is a TS model that enables simulation of charged particle transport in liquid water medium down to $\sim 10 \mathrm{eV}$ energies [55,62-64]. In their study, Sakata et al. [65,66] have developed TS physics extension for the Geant4-DNA toolkit, to simulate the physical interactions of electrons in gold apart from liquid water. This extension has been compared to Geant4 Penelope and Livermore models in AuNPs enhanced RT simulation [61]. Geant4-DNA has been already used to model the cellular effect of AuNPs upon irradiation $[12,67,68]$ and to calculate radial dose distribution and chemical species production around one AuNP irradiated by a proton beam [69].

Concerning EGSnrc, it is a general purpose package for the MC simulation of photons and electrons transport for energies ranging from $1 \mathrm{keV}$ to $10 \mathrm{GeV}$. Since it is a $\mathrm{CH}$ code, none nanodosimetric MC study has been performed using EGSnrc for dose calculations. However,
Martinov et al. [41] used EGSnrc code to develop a heterogeneous multiscale model for AuNPs radiosensitization and they concluded that their approach could be efficient for both macrodosimetry and microdosimetry.

MCNPX [29,30,37,70,71] and MCNP5 [24,36,47] codes have been also used in some macrodosimetric studies. Lechtman et al. [24] have combined MCNP5 and PENELOPE codes to simulate the production and transport of Auger electrons producing from photons-AuNPs interactions for achieving highest accuracy in dose evaluation while later on they developed a MC based AuNPs radiosensitization predictive model (ARP) [72]. PENELOPE code has been also used in different simulations by Kirkby et al. who suggested that the targeting of cancer cells mitochondria instead of nucleous could be proved an important component of the radiation damages induced by AuNPs [16], and discussed the scenario of kV GEART [35].

In terms of TS codes, apart from Geant4-DNA code, NOREC code has been used in MC studies to study electrons distribution in water [22,73]. NOREC is based on an event by event electron transport in water algorithm for the energy range from $7.4 \mathrm{eV}$ to $1 \mathrm{MeV}$. Since NOREC has been compared with other $\mathrm{CH}[74]$ and TS Monte Carlo codes [75,76] it is expected to produce valid results in nanodosimetric studies. The use of TS codes or the fine tuning of the simulation parameters in case a $\mathrm{CH}$ code is chosen $[55,64]$ are highly recommended in order to gain accurate results when performing dosimetry in nanosized volumes.

\subsubsection{Modelling types (nanospheres, gold-water mixture, clusters)}

Evidence from studies over the last years suggests that AuNPs tend to form clusters once they enter human body $[31,77,78]$. In their MC study, Francis et al. [79] found that the model of AuNPs loaded clusters of vesicles irradiated with $\mathrm{kV}$ photons could lead to higher enhancement ratios than that of AuNPs uniform distribution. However, different types of AuNPs simulation geometries have been presented to literature. The most common models investigated in MC studies are the single AuNPs $[12,24,25,29,30,37,39,68,80]$, AuNPs clusters [15,31] and the goldwater mixture $[22,33,39,80]$.

Modelling Ir-192 irradiation, Zhang et al. [80] compared gold-water mixture to single AuNPs uniformly distributed and concluded that the former model overestimates dose enhancement by $16 \%$. Similar were the findings from Koger et al. [39] who tried to explain the observed differences and establish a method to convert dose from macroscopic simulations, where the medium is modelled as a gold-tissue mixture, to a "mean dose-to-tissue" on a microscopic scale. They have also found that the difference between the two models is energy, AuNPs size and concentration dependent in the energy range from 2 to $100 \mathrm{keV}$, while for energy greater than $200 \mathrm{keV}$ or lower than $2 \mathrm{keV}$, the dose enhancement is similar for the two models. Finally, they concluded that in gold-water mixture, the energy is absorbed from the surrounding medium in contrast to individual AuNPs modelling where there the energy is deposited inside the NPs. This finding is supported in a similar published study by Martinov et al. [41] who introduced the "heterogeneous multiscale (HetMS) model" for MC simulations of AuNPs dose-enhanced radiation therapy. The ideal and probably unrealistic scenario of the uniform distribution of AuNPs inside a tumor region has been proven more effective for dose enhancement than non-uniform for all AuNPs sizes and photon beam energies [38].

Two different models were examined in a study by Douglass et al. [28] who created a virtual 3D cell according to the dimensions of a typical keratinocyte cell, containing five key regions. In the first scenario, a $400 \mathrm{~nm}$ cluster of AuNPs was positioned randomly in the cytoplasm of the cell at four different positions while in the second, a $300 \mathrm{~nm}$ gold layer surrounded cell's nucleus. In the first case, no statistical significant difference was found in the deposited energy in contrast to the second one where a significant increase in energy was observed in any cell region. Instead of the gold-water mixture model, a case in which AuNPs are positioned in the center of $1 \mu \mathrm{m}$ networks inside a modelled cubic tumor mass was examined and proven more effective 


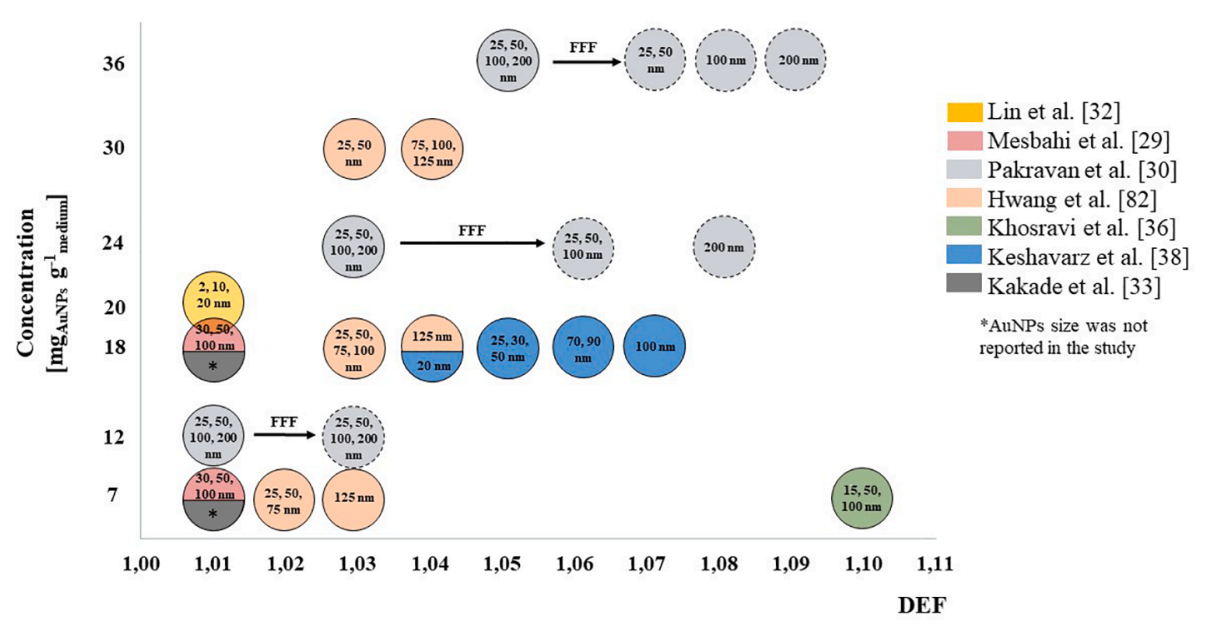

Fig. 1. AuNPs size and concentration impact on DEF in MC studies simulating AuNPs loaded regions irradiation with MV photon beams. The circles with dashed line represent results from FFF photon beams irradiation.

in dose enhancement [36].

\section{Discussion}

Theoretical models in literature have confirmed the fact that AuNPs can enhance the energy transferred to the medium they are incorporated to and the subsequent biological damages upon irradiation. Various MC studies and analytical calculations have investigated in depth different aspects of AuNPs and MV photon beams. In silico studies offer the chance to evaluate various combinations of simulation models and geometries to conclude in trustworthy results regarding optimization of AuNPs driven RT.

As far as AuNPs size is concerned, while greater AuNPs imply greater number of photon-NPs interaction, the increased levels in self absorption of the secondary electrons produced should be taken into consideration. Moreover, it seems that AuNPs size has a significant impact in $\mathrm{kV}$ photons irradiation, while in $\mathrm{MV}$ region concentration is more important. A major limit in the MC research concerning AuNPs concentration evaluation is the computational power. For instance, a typical concentration of $7 \mathrm{mg}$ Au per $\mathrm{g}$ of tissue or water, could be translated to $10^{16}$ AuNPs in $1 \mathrm{~cm}^{3}$ of tissue or water depending on AuNPs size [41]. This number of AuNPs simulation may be time consuming and probably this is the reason why we lack of good and trustworthy theoretical evidence concerning the correlation between AuNPs efficiency and toxicity levels. Without a doubt, the optimum combination of the ideal AuNPs size and their concentration is a crucial matter, since it drives their biodistribution, excretion routes, toxicity and finally the cost of the potential therapies that involve them. In Fig. 1 we summarize some of the MC simulations that studied the impact of AuNPs characteristics in DEF. As can be seen, AuNPs concentration has a clear impact on DEF, while the effect of size alone is not well established.

The exact position of AuNPs inside a tumor region and relative to cell's nucleus along with the type of AuNPs distribution play a major role in dose enhancement levels in MC studies. Homogeneous models or discrete modelling of single gold nanospheres that have been simulated in many studies probably do not represent the in vivo distribution of AuNPs once they enter tumor tissues. Clustering instead, has been proved a more possible mechanism of AuNPs diffusion and should be carefully designed and evaluated in MC studies [21,79,81].

Regarding photon beams characteristics, we expect that the irradiation of AuNPs loaded areas with photons in the $\mathrm{kV}$ range will be more efficient to achieve an important dose amplification than in MV. From the reported MC studies in the MV region, increasing photon field size seems to be corellated with greater dose enhancement $[15,16]$. Substantial levels of dose enhancement have been predicted for areas out of photon beam's central axis (the greatest values among published results), and for split IMRT fields [15]. Finally the irradiation of AuNPs injected tumors with FFF photon beams has been proven more effective in terms of dose enhancement, a fact which could offer a novel approach for modern RT techniques.

\section{Conclusion}

MC simulations are a really useful tool that could assist the scientific community to investigate any aspects implemented in AuNPs enhanced RT (physical and biological mechanisms) and study in depth the degree of dose enhancement from different clinical scenarios. Strong emphasis should be placed on the carefull comparisons among modelling results, since there exist a great amount of different protocols published in literature.

From the physicists perspective, further investigation is required on the low energy component of photon spectrum and applying the results from nanodosimetric studies with AuNPs in macrodosimetry (e.g. in radiation treatment planning softwares). In silico studies should be focused on using TS codes to model particles transport not only in liquid water areas, but also in the gold nanosized volumes.

Theoretical studies with AuNPs should be realistic enough to be represented in vitro and in vivo. In reverse, the biological models regarding AuNPs radiosensitising properties (cellular targeting and response, AuNPs biodistribution) require detailed investigation to be implemented in silico and be correlated to physical ones. We should keep in mind that the different findings of theoretical studies compared to experimental concerning AuNPs efficacy $[20,21]$ could be attributed to the fact that their contribution in tumor control upon photons irradiation is not only physically but also biologically driven [32,79,82]. The recent progress in DNA damages prediction in silico [83] combined with the steps towards nanodosimetric MC studies $[84,85]$ could offer an accurate insight into the phenomenon of AuNPs radioenhancement effect from both biological and physical point of view.

Finally, the cross evaluation between theory and experiment is the way to go a step closer to clinical use and follow a safe saway towards personalized RT. Research efforts should be devoted in clarifying the optimum AuNPs characteristics and the ideal RT technique that will cause the greatest dose enhancement, with less side effects.

\section{Acknowledgements}

The present work was co-funded by the European Union and Greek national funds through the Operational Program "Human Resources Development, Education and Lifelong Learning " (NSRF 2014-2020), 
under the call "Supporting Researchers with an Emphasis on Young Researchers - Cycle B" (MIS:5048154).

\section{References}

[1] Atun R, Jaffray DA, Barton MB, Bray F, Baumann M, Vikram B, et al. Expanding global access to radiotherapy. Lancet Oncol 2015;16:1153-86.

[2] Gu YJ, Cheng J, Lin CC, Lam YW, Cheng SH, Wong WT. Nuclear penetration of surface functionalized gold nanoparticles. Toxicol Appl Pharmacol 2009;237: 196-204.

[3] Hainfeld JF, Slatkin DN, Smilowitz HM. The use of gold nanoparticles to enhance radiotherapy in mice. Phys Med Biol 2004;49:N309-15.

[4] Lasagna-Reeves C, Gonzalez-Romero D, Barria MA, Olmedo I, Clos A, Sadagopa Ramanujam VM, et al. Bioaccumulation and toxicity of gold nanoparticles after repeated administration in mice. Biochem Biophys Res Commun 2010;393:649-55.

[5] Albanese A, Tang PS, Chan WC. The effect of nanoparticle size, shape, and surface chemistry on biological systems. Annu Rev Biomed Eng 2012;14:1-16.

[6] He Z, Li C, Zhang X, Zhong R, Wang H, Liu J, et al. The effects of gold nanoparticles on the human blood functions. Artif Cells Nanomed Biotechnol 2018;46:720-6.

[7] Ali MRK, Wu Y, Ghosh D, Do BH, Chen K, Dawson MR, et al. Nuclear MembraneTargeted Gold Nanoparticles Inhibit Cancer Cell Migration and Invasion. ACS Nano 2017;11:3716-26.

[8] Chithrani DB, Jelveh S, Jalali F, van Prooijen M, Allen C, Bristow RG, et al. Gold nanoparticles as radiation sensitizers in cancer therapy. Radiat Res 2010;173: $719-28$.

[9] Hainfeld JF, Dilmanian FA, Zhong Z, Slatkin DN, Kalef-Ezra JA, Smilowitz HM. Gold nanoparticles enhance the radiation therapy of a murine squamous cell carcinoma. Phys Med Biol 2010;55:3045-59.

[10] Liu CJ, Wang CH, Chen ST, Chen HH, Leng WH, Chien CC, et al. Enhancement of cell radiation sensitivity by pegylated gold nanoparticles. Phys Med Biol 2010;55: 931-45.

[11] Jain S, Coulter JA, Hounsell AR, Butterworth KT, McMahon SJ, Hyland WB, et al. Cell-specific radiosensitization by gold nanoparticles at megavoltage radiation energies. Int J Radiat Oncol Biol Phys 2011;79:531-9.

[12] McMahon SJ, Hyland WB, Muir MF, Coulter JA, Jain S, Butterworth KT, et al. Nanodosimetric effects of gold nanoparticles in megavoltage radiation therapy. Radiother Oncol J Eur Soc Therapeut Radiol Oncol 2011;100:412-6.

[13] Hainfeld JF, Smilowitz HM, O'Connor MJ, Dilmanian FA, Slatkin DN. Gold nanoparticle imaging and radiotherapy of brain tumors in mice. Nanomedicine 2013;8:1601-9.

[14] Joh DY, Sun L, Stangl M, Al Zaki A, Murty S, Santoiemma PP, et al. Selective targeting of brain tumors with gold nanoparticle-induced radiosensitization. PLoS ONE 2013;8:e62425.

[15] Tsiamas P, Liu B, Cifter F, Ngwa WF, Berbeco RI, Kappas C, et al. Impact of beam quality on megavoltage radiotherapy treatment techniques utilizing gold nanoparticles for dose enhancement. Phys Med Biol 2013;58:451-64.

[16] Kirkby C, Ghasroddashti E. Targeting mitochondria in cancer cells using gold nanoparticle-enhanced radiotherapy: a Monte Carlo study. Med Phys 2015;42: 1119-28.

[17] Wolfe T, Chatterjee D, Lee J, Grant JD, Bhattarai S, Tailor R, et al. Targeted gold nanoparticles enhance sensitization of prostate tumors to megavoltage radiation therapy in vivo. Nanomedicine. 2015;11:1277-83.

[18] Guo M, Sun Y, Zhang X-D. Enhanced radiation therapy of gold nanoparticles in liver cancer. Appl Sci 2017;7:232.

[19] Mousavi Anijdan SH, Shirazi A, Mahdavi AR, Ezzati A, Mofid B, Khoei S, et al. Megavoltage dose enhancement of gold nanoparticles for different geometric setups: Measurements and monte carlo simulation. Int J Radiat Res 2012;10.

[20] Butterworth KT, McMahon SJ, Taggart LE, Prise KM. Radiosensitization by gold nanoparticles: effective at megavoltage energies and potential role of oxidative stress. Translat Cancer Res 2013;2:269-79.

[21] Kirkby C, Koger B, Suchowerska N, McKenzie DR. Dosimetric consequences of gold nanoparticle clustering during photon irradiation. Med Phys 2017:44:6560-9.

[22] Jones BL, Krishnan S, Cho SH. Estimation of microscopic dose enhancement factor around gold nanoparticles by Monte Carlo calculations. Med Phys 2010;37: $3809-16$.

[23] Berbeco RI, Ngwa W, Makrigiorgos GM. Localized dose enhancement to tumor blood vessel endothelial cells via megavoltage X-rays and targeted gold nanoparticles: new potential for external beam radiotherapy. Int J Radiat Oncol Biol Phys 2011;81:270-6.

[24] Lechtman E, Chattopadhyay N, Cai Z, Mashouf S, Reilly R, Pignol JP. Implications on clinical scenario of gold nanoparticle radiosensitization in regards to photon energy, nanoparticle size, concentration and location. Phys Med Biol 2011;56: $4631-47$.

[25] Leung MK, Chow JC, Chithrani BD, Lee MJ, Oms B, Jaffray DA. Irradiation of gold nanoparticles by x-rays: Monte Carlo simulation of dose enhancements and the spatial properties of the secondary electrons production. Med Phys 2011;38: 624-31.

[26] Amato E, Italiano A, Pergolizzi S. Gold nanoparticles as a sensitising agent in external beam radiotherapy and brachytherapy: a feasibility study through Monte Carlo simulation. Int J Nanotechnol 2013;10:1045-54.

[27] Detappe A, Tsiamas P, Ngwa W, Zygmanski P, Makrigiorgos M, Berbeco R. The effect of flattening filter free delivery on endothelial dose enhancement with gold nanoparticles. Med Phys 2013;40:031706.
[28] Douglass M, Bezak E, Penfold S. Monte Carlo investigation of the increased radiation deposition due to gold nanoparticles using kilovoltage and megavoltage photons in a 3D randomized cell model. Med Phys 2013;40:071710.

[29] Mesbahi A, Jamali F, garehaghaji N. Effect of photon beam energy, gold nanoparticle size and concentration on the dose enhancement in radiation therapy. BioImpacts: BI 2013;3:29-35. https://doi.org10.5681/bi.2013.002.

[30] Pakravan D, Ghorbani M, Momennezhad M. Tumor dose enhancement by gold nanoparticles in a 6 MV photon beam: a Monte Carlo study on the size effect of nanoparticles. Nukleonika 2013;58.

[31] Zygmanski P, Liu B, Tsiamas P, Cifter F, Petersheim M, Hesser J, et al. Dependence of Monte Carlo microdosimetric computations on the simulation geometry of gold nanoparticles. Phys Med Biol 2013;58:7961-77.

[32] Lin Y, McMahon SJ, Scarpelli M, Paganetti H, Schuemann J. Comparing gold nanoparticle enhanced radiotherapy with protons, megavoltage photons and kilovoltage photons: a Monte Carlo simulation. Phys Med Biol 2014;59:7675-89.

[33] Kakade N, Sharma S. Dose enhancement in gold nanoparticle-aided radiotherapy for the therapeutic photon beams using Monte Carlo technique. J Cancer Res Ther 2015;11:94-7.

[34] Lin Y, Paganetti H, McMahon SJ, Schuemann J. Gold nanoparticle induced vasculature damage in radiotherapy: comparing protons, megavoltage photons, and kilovoltage photons. Med Phys 2015;42:5890-902.

[35] Koger B, Kirkby C. Optimization of photon beam energies in gold nanoparticle enhanced arc radiation therapy using Monte Carlo methods. Phys Med Biol 2016; 61:8839-53.

[36] Khosravi H, Mahdavi A, Rahmani F, Ebadi A. The impact of nano-sized gold particles on the target dose enhancement based on photon beams using by Monte Carlo Method. Nanomed Res J 2016;1:84-9.

[37] Hwang C, Kim JM, Kim J. Influence of concentration, nanoparticle size, beam energy, and material on dose enhancement in radiation therapy. J Radiat Res 2017; 58:405-11.

[38] Keshavarz S, Sardari D. Different distributions of gold nanoparticles on the tumor and calculation of dose enhancement factor by Monte Carlo simulation. Nucl Energy Technol 2019;5:361-71.

[39] Koger B, Kirkby C. A method for converting dose-to-medium to dose-to-tissue in Monte Carlo studies of gold nanoparticle-enhanced radiotherapy. Phys Med Biol 2016;61:2014-24.

[40] Zhang XD, Wu D, Shen X, Chen J, Sun YM, Liu PX, et al. Size-dependent radiosensitization of PEG-coated gold nanoparticles for cancer radiation therapy. Biomaterials 2012;33:6408-19.

[41] Martinov MP, Thomson RM. Heterogeneous multiscale Monte Carlo simulations for gold nanoparticle radiosensitization. Med Phys 2017;44:644-53.

[42] Makris D, Spirou SV, Loudos G. Does the setup of Monte Carlo simulations influence the calculated properties and effect of gold nanoparticles? Phys Med Eur J Med Phys 2014;30:e111.

[43] Retif P, Bastogne T, Barberi-Heyob M. Robustness analysis of a Geant4-GATE simulator for nanoradiosensitizers characterization. IEEE Trans Nanobiosci 2016; 15:209-17.

[44] Sah B, Antosh M. Effect of size on gold nanoparticles in radiation therapy: Uptake and survival effects. J Nano Med 2019;1013.

[45] Vales G, Suhonen S, Siivola KM, Savolainen KM, Catalán J, Norppa H. Genotoxicity and cytotoxicity of gold nanoparticles in vitro: role of surface functionalization and particle size. Nanomaterials 2020;10:271.

[46] Paro AD, Hossain M, Webster TJ, Su M. Monte Carlo and analytic simulations in nanoparticle-enhanced radiation therapy. Int J Nanomed 2016;11:4735-41.

[47] Cai Z, Pignol JP, Chattopadhyay N, Kwon YL, Lechtman E, Reilly RM. Investigation of the effects of cell model and subcellular location of gold nanoparticles on nuclear dose enhancement factors using Monte Carlo simulation. Med Phys 2013; 40:114101.

[48] Geng F, Song K, Xing JZ, Yuan C, Yan S, Yang Q, et al. Thio-glucose bound gold nanoparticles enhance radio-cytotoxic targeting of ovarian cancer. Nanotechnology 2011;22:285101.

[49] Wang C, Jiang Y, Li X, Hu L. Thioglucose-bound gold nanoparticles increase the radiosensitivity of a triple-negative breast cancer cell line (MDA-MB-231). Breast Cancer (Tokyo, Japan) 2015;22:413-20.

[50] Sung W, Schuemann J. Energy optimization in gold nanoparticle enhanced radiation therapy. Phys Med Biol 2018;63:135001. https://doi.org10.1088/13616560 /aacab6.

[51] Xiao Y, Kry SF, Popple R, Yorke E, Papanikolaou N, Stathakis S, et al. Flattening filter-free accelerators: a report from the AAPM therapy emerging technology assessment work group. J Appl Clin Med Phys 2015;16:12-29.

[52] Bencheikh M, Maghnouj A, Tajmouati J, Didi A. Study of the volume reduction impact on secondary photons emergent from flattening filter for high radiotherapy quality. 2019;25:23. https://doi.org10.2478/pjmpe-2019-0004.

[53] Heuvel FVd, Jean-Pierre L, Nuyts S. Beam energy considerations for gold nanoparticle enhanced radiation treatment. Phys Med Biol 2010;55:4509. https://doi. org10.1088/0031-9155/55/16/S06.

[54] Perkins ST, Cullen DE, Seltzer SM. Tables and graphs of electron-interaction cross sections from $10 \mathrm{eV}$ to $100 \mathrm{GeV}$ derived from the LLNL Evaluated Electron Data Library (EEDL), Z = 1-100. United States; 1991.

[55] Kyriakou I, Ivanchenko V, Sakata D, Bordage MC, Guatelli S, Incerti S, et al. Influence of track structure and condensed history physics models of Geant4 to nanoscale electron transport in liquid water. Physica medica : PM : an international journal devoted to the applications of physics to medicine and biology : official journal of the Italian Association of Biomedical Physics (AIFB). 2019;58:149-54.

[56] Incerti S, Suerfu B, Xu J, Ivantchenko V, Mantero A, Brown JMC, et al. Simulation of Auger electron emission from nanometer-size gold targets using the Geant4 
Monte Carlo simulation toolkit. Nucl Instrum Methods Phys Res Sect B 2016;372: 91-101.

[57] Bhan K, Spanier J. Condensed history Monte Carlo methods for photon transport problems. J Comput Phys 2007;225:1673-94.

[58] Xie W, Li J, Li C, Qiu R, Yan C, Zeng Z. Comparison of direct DNA strand break simulated with different DNA models. Radiat Prot Dosim 2013;156:283-8.

[59] Chatzipapas KP, Papadimitroulas P, Obeidat M, McConnell KA, Kirby N, Loudos G, et al. Quantification of DNA double-strand breaks using Geant4-DNA. Med Phys 2019;46:405-13.

[60] Incerti S, Kyriakou I, Bernal MA, Bordage MC, Francis Z, Guatelli S, et al. Geant4DNA example applications for track structure simulations in liquid water: A report from the Geant4-DNA Project. Med Phys 2018.

[61] Sakata D, Kyriakou I, Okada S, Tran HN, Lampe N, Guatelli S, et al. Geant4-DNA track-structure simulations for gold nanoparticles: The importance of electron discrete models in nanometer volumes. Med Phys 2018;45:2230-42.

[62] Bernal MA, Bordage MC, Brown JMC, Davídková M, Delage E, El Bitar Z, et al. Track structure modeling in liquid water: A review of the Geant4-DNA very low energy extension of the Geant4 Monte Carlo simulation toolkit. Physica medica : PM : an international journal devoted to the applications of physics to medicine and biology : official journal of the Italian Association of Biomedical Physics (AIFB) 2015;31:861-74.

[63] Incerti S, Douglass M, Penfold S, Guatelli S, Bezak E. Review of Geant4-DNA applications for micro and nanoscale simulations. Phys Med 2016;32:1187-200.

[64] Kyriakou I, Emfietzoglou D, Ivanchenko V, Bordage MC, Guatelli S, Lazarakis P, et al. Microdosimetry of electrons in liquid water using the low-energy models of Geant4. J Appl Phys 2017;122:024303.

[65] Sakata D, Incerti S, Bordage MC, Lampe N, Okada S, Emfietzoglou D, et al. An implementation of discrete electron transport models for gold in the Geant 4 simulation toolkit. J Appl Phys 2016;120:244901.

[66] Sakata D, Kyriakou I, Tran HN, Bordage M-C, Rosenfeld A, Ivanchenko V, et al. Electron track structure simulations in a gold nanoparticle using Geant4-DNA. Phys Med Eur J Med Phys 2019;63:98-104.

[67] McMahon SJ, Hyland WB, Muir MF, Coulter JA, Jain S, Butterworth KT, et al. Biological consequences of nanoscale energy deposition near irradiated heavy atom nanoparticles. Sci Rep 2011;1:18.

[68] He C, C.L. Chow J. Gold nanoparticle DNA damage in radiotherapy: A Monte Carlo study. AIMS Bioengineering. 2016;3:352-61. https://doi.org10.3934/ bioeng.2016.3.352.

[69] Tran HN, Karamitros M, Ivanchenko VN, Guatelli S, McKinnon S, Murakami K, et al. Geant4 Monte Carlo simulation of absorbed dose and radiolysis yields enhancement from a gold nanoparticle under $\mathrm{MeV}$ proton irradiation. Nucl Instrum Methods Phys Res Sect B 2016;373:126-39.

[70] Khadem Abolfazli M, Mahdavi SR, Ataei G. Studying effects of gold nanoparticle on dose enhancement in megavoltage radiation. J Biomed Phys Eng 2015;5:185-90.
[71] Rasouli FS, Masoudi SF, Asadi S. On the importance of modeling gold nanoparticles distribution in dose-enhanced radiotherapy. Int J Nanomed 2019;14:5865-74.

[72] Lechtman E, Mashouf S, Chattopadhyay N, Keller BM, Lai P, Cai Z, et al. A Monte Carlo-based model of gold nanoparticle radiosensitization accounting for increased radiobiological effectiveness. Phys Med Biol 2013:58:3075-87.

[73] Chow JCL, Leung MKK, Fahey S, Chithrani DB, Jaffray DA. Monte Carlo simulation on low-energy electrons from gold nanoparticle in radiotherapy. J Phys Conf Ser 2012;341:012012.

[74] Cho SH, Vassiliev ON, Horton JL. Comparison between an event-by-event Monte Carlo code, NOREC, and ETRAN for electron scaled point kernels between $20 \mathrm{keV}$ and $1 \mathrm{MeV}$. Radiat Environ Biophys 2007;46:77-83.

[75] Lucido J, Popescu I, Moiseenko V. SU-E-T-81: comparison of microdosimetric quantities calculated using the track structure Monte Carlo Algorithms Geant4DNA and NOREC. Med Phys 2014;41:240. https://doi.org10.1118/1.4888411.

[76] Dingfelder M, Ritchie RH, Turner JE, Friedland W, Paretzke HG, Hamm RN. Comparisons of Calculations with PARTRAC and NOREC: Transport of Electrons in Liquid Water. Radiat Res 2008;169(584-94):11.

[77] Liu M, Li Q, Liang L, Li J, Wang K, Li J, et al. Real-time visualization of clustering and intracellular transport of gold nanoparticles by correlative imaging. Nat Commun 2017;8:15646. https://doi.org10.1038/ncomms15646.

[78] Cepeda-Pérez E, de Jonge N. Dynamics of gold nanoparticle clusters observed with liquid-phase electron microscopy. Micron 2019;117:68-75.

[79] Francis Z, Montarou G, Incerti S, Bernal M, Zein SA. A simulation study of gold nanoparticles localisation effects on radiation enhancement at the mitochondrion scale. Phys Med 2019;67:148-54.

[80] Zhang SX, Gao J, Buchholz TA, Wang Z, Salehpour MR, Drezek RA, et al. Quantifying tumor-selective radiation dose enhancements using gold nanoparticles: a monte carlo simulation study. Biomed Microdevices 2009;11: 925-33.

[81] Byrne H, McNamara A, Kuncic Z. Impact of nanoparticle clustering on dose radioenhancement. Radiat Prot Dosim 2019;183:50-4.

[82] McQuaid HN, Muir MF, Taggart LE, McMahon SJ, Coulter JA, Hyland WB, et al. Imaging and radiation effects of gold nanoparticles in tumour cells. Sci Rep 2016;6: 19442.

[83] Mavragani IV, Nikitaki Z, Kalospyros SA, Georgakilas AG. Ionizing radiation and complex DNA damage: from prediction to detection challenges and biological significance. Cancers (Basel) 2019;11:1789.

[84] Lazarakis P, Incerti S, Ivanchenko V, Kyriakou I, Emfietzoglou D, Corde S, et al. Investigation of Track Structure and Condensed History physics models for applications in radiation dosimetry on a micro and nano scale in Geant4. Biomed Phys Eng Express 2018;4.

[85] Nikjoo H, Emfietzoglou D, Liamsuwan T, Taleei R, Liljequist D, Uehara S. Radiation track, DNA damage and response-a review. Rep Prog Phys Phys Soc (Great Britain) 2016;79:116601. 